Research Article

\title{
Study on Fire Resistance Ability and Mechanical Properties of Composites Based on Epikote 240 Epoxy Resin and Thermoelectric Fly Ash: An Ecofriendly Additive
}

\author{
Tuan Anh Nguyen (D), Quang Tung Nguyen, Xuan Canh Nguyen (iD, and Van Hoan Nguyen \\ Faculty of Chemical Technology, Hanoi University of Industry (HaUI), No. 298 Cau Dien, North Tu Liem District, \\ Hanoi, Vietnam \\ Correspondence should be addressed to Tuan Anh Nguyen; anhnt@haui.edu.vn
}

Received 16 March 2019; Accepted 2 May 2019; Published 16 June 2019

Guest Editor: Van Duong Dao

Copyright (c) 2019 Tuan Anh Nguyen et al. This is an open access article distributed under the Creative Commons Attribution License, which permits unrestricted use, distribution, and reproduction in any medium, provided the original work is properly cited.

In this study, fly ash was tested as a filler in epoxy with concentrations of 5, 10, and $20 \mathrm{wt} . \%$. Fly ash particles were modified by chemical treatments (using $\mathrm{NaOH}$ and $\mathrm{HCl}$ ) to enhance the compatibility and adhesion, making mechanical properties and flame retardancy of materials better. Flexural strength, tensile strength, and impact resistance decrease as fly ash content increases. The compressive strength is further increased by the addition of fly ash (compressive strength of the materials including 5, 10, 20 wt.\% of fly ash modified with $\mathrm{NaOH}$ is $176.01,189.90$, and $197.07 \mathrm{MPa}$, respectively). The interface between fly ash and epoxy matrix plays an important role in determining the mechanical strength and flame retardancy of synthetic materials. The results of UL94HB and LOI test method for composite materials including $20 \mathrm{wt} . \%$ fly ash (modified by $\mathrm{NaOH}$ ) reached $13.45 \mathrm{~mm} / \mathrm{min}$ and $22.4 \%$, respectively. These results showed that fly ash is an efficient additive as a flame retardant which decreases the amounts of additives in products and improves their efficiency. Fly ash was also dispersed into epoxy resin to enhance its resistance to oxidation.

\section{Introduction}

Flame retardants (FRs) used as additives in a wide range of production play a very important role in suppressing fire generation and delaying fire spread $[1,2]$. A composite material based on epoxy resin and fly ash (a by-product from thermal power plan) with a good fire resistance ability was developed. Fly ash used as a flame retardant instead of current ones (for example, organic halogen compounds) reduces environmental problems when compared to using flame retardant epoxy resin [3]. Some popular commercial flame retardants are not only dangerous to human and environment but they also have negative effects on mechanical properties of materials [4]. For this reason, it is necessary to find an ecofriendly material which is harmless to human. Additives such as clay and fly ash are being paid great attention. Many authors studied the use of ecofriendly additives such as fly ash, multiwalled carbon nanotube, and nanoclay in enhancing fire resistance of epoxy resin [5-7]. In this study, ultrafine fly ash has been used. Fly ash has been surface-treated with $\mathrm{NaOH}$ and $\mathrm{HCl}$ acid to improve dispersion in Epikote 240 epoxy matrix. The purpose of this study was to improve fire retardancy and improve some mechanical durability, thereby expanding the application area of fly ash for thermal power plants in Vietnam and reducing the impact on the environment. Methods such as UL 94 and limiting oxygen index (LOI) are used to study the combustibility of composites.

\section{Materials and Methods}

\subsection{Materials}

(i) Epikote 240 (EP) epoxy resin from Shell Chemicals (USA) with epoxy group content of $24.6 \%, \mathrm{Mw}$ $5100-5400 \mathrm{mmol} / \mathrm{kg}$, density $1.12 \mathrm{~g} / \mathrm{cm}^{3}$, and 
viscosity at $25^{\circ} \mathrm{C} 007-1.1 \mathrm{~Pa} \cdot \mathrm{s}$. Diethylenetriamine (DETA) from Dow Chemicals (USA), with density $0.953 \mathrm{~g} / \mathrm{cm}^{3}$ at $20^{\circ} \mathrm{C}$, boiling point $207^{\circ} \mathrm{C}$, and $\mathrm{Mw}$ $103.2 \mathrm{gmol}^{-1}$. $\mathrm{HCl}$ and $\mathrm{NaOH}$ from Dow Chemicals (USA).

(ii) The fly ash primarily consisted of inorganic materials such as silica, alumina, and calcium oxide. Fly ash taken from the ash waste of Pha Lai Thermal Power Station was collected from Song Da Joint Stock Company 12-Cao Cuong, Vietnam.

\subsection{Methods}

2.2.1. Sample Preparation. First, the fly ash was kept in a drier at $100^{\circ} \mathrm{C}$ for 24 hours to remove the moisture present in it. After $24 \mathrm{hrs}$, the fly ash was taken out of the drier. Then, the amount of fly ash, epoxy resin (Epikote 240), and hardener (DETA) was calculated for five different composites $(0,5,10$, and 20 w.\% fly ash). Curing was performed at room temperature for approx. $24 \mathrm{hrs}$. After curing, the mould was opened, and the slab was taken out of the mould and cleaned and cured under room temperature for 1 and 7 days.

\subsubsection{Characterizations}

(i) The morphology of the samples was carried out by scanning electron microscopy (SEM, Evacseq error codes, S-4800, Japan). An ultramicrotome (Leica microsystem) was used to cut ultrathin sections (80 nm) of samples before recovered on a copper grid.

(ii) The flame retardant properties was tested by the limiting oxygen index (LOI) (Yasuda Seiki Seisakusho Ltd, Japan) according to JIS K720-1976, with sheet dimensions of $120 \times 6.5 \times 3.2 \mathrm{~mm}$.

(iii) The UL-94 rating was tested according to the UL-94 (ASTMD635-12) with sheet dimensions of $125 \pm 5 \mathrm{~mm}$ length by $13.0 \pm 0.5 \mathrm{~mm}$ width and with the minimum thickness of $3.0(-0.0+0.2) \mathrm{mm}$.

(iv) The combustion rate was measured by COMBUSTION RESISTANCE COD 6145000 according to ASTM D757-77 standard. The specimen's dimensions were $3.17 \times 12.7 \times 121 \mathrm{~mm}^{3}$. Mechanical properties were measured on an INSTRON-5582 $100 \mathrm{KN}$ (USA) according to ISO 527-1993 at an extension speed of $5 \mathrm{~mm} / \mathrm{min}$.

(v) All data were the average of five independent measurements; the relative errors committed on each data were reported as well. IR spectrum was measured at the Department of Chemistry, University of Natural Sciences (Hanoi National University).

\section{Results and Discussion}

3.1. Investigation of Characteristics of Fly Ash. Fly ash from the ash waste of Pha Lai Thermal Power Station was collected in Song Da Joint Stock Company 12-Cao Cuong, Vietnam.
Before the investigation, fly ash was washed by acetone to remove impurities. Scanning electronic microscopy (SEM) was used to determine fly ash particles' morphological structure. The results are shown in Figure 1. As seen in Figure 1, fly ash particles have spherical smooth structure. They are abundant and different in size.

In Figure 2, the IR spectroscopy of fly ash with vibration bands $400-4000 \mathrm{~cm}^{-1}$ shows that there is a peak at $3649 \mathrm{~cm}^{-1}$ and $1065 \mathrm{~cm}^{-1}$ corresponding to $-\mathrm{OH}$ (free) and $\mathrm{Si}-\mathrm{O}$, respectively, proving the presence of -OH in fly ash's surface, thus making it easier for the modification process to attach silane groups to fly ash's surface to enhance compatibility between inorganic material and polymer substrate. Besides, there are also peaks at $792 \mathrm{~cm}^{-1}, 562 \mathrm{~cm}^{-1}$ and $480 \mathrm{~cm}^{-1}$, and $452 \mathrm{~cm}^{-1}$ corresponding to the presence of quartz, $\mathrm{O}-\mathrm{Fe}$, and $\mathrm{O}-\mathrm{Al}$, respectively.

\subsection{Treatment of Fly Ash's Surface}

\subsubsection{Treatment of Fly Ash's Surface with $\mathrm{NaOH}$}

(1) IR Spectroscopy of Fly Ash Modified with $\mathrm{NaOH}$. $\mathrm{NaOH}$ is a strong base containing active hydroxide groups. $\mathrm{NaOH}$ with concentration of $3 \mathrm{M}$ was used to modify fly ash. In the modification process, fly ash particles were stirred in $3 \mathrm{M}$ solution of $\mathrm{NaOH}$ at $80^{\circ} \mathrm{C}$ for 5 hours. Efficiency of the process is qualitatively evaluated through IR spectroscopy of modified fly ash (Figure 3).

Figure 3 shows that there are new peaks at $3451 \mathrm{~cm}^{-1}$ and $1653 \mathrm{~cm}^{-1}$ in IR spectra of modified fly ash in comparison with spectra of initial fly ash. In IR spectra, there is the appearance of a peak at $3451 \mathrm{~cm}^{-1}$ and $1653 \mathrm{~cm}^{-1}$ corresponding to the stretching vibrations of $-\mathrm{OH}$ groups of $\mathrm{NaOH}$ and $\mathrm{H}_{2} \mathrm{O}$, respectively. On other hand, there is no change in the fingerprint region, indicating that metallic oxides exist on modified fly ash. Therefore, it can be said that the structure of fly ash is quite stable.

(2) Effects of Alkaline Treatment on Fly Ash's Size and Surface Area. The surface of initial fly ash is smooth, making it difficult for adhesion between fly ash and polymer substrate. So, it is necessary to treat fly ash surface to increase roughness and surface area or form active groups on the surface.

Fly ash modified with $\mathrm{NaOH}$ was filtered, washed, and dried. The contribution of fly ash particles is observed by the SEM method in low resolution.

In Figure 4, the SEM image of fly ash modified with $\mathrm{NaOH}$ shows that when the contribution of $\mathrm{NaOH}$ is higher, the size of modified fly ash particles is more even in comparison with initial ones. In other words, $\mathrm{NaOH}$ makes the size of fly ash particles smaller.

The morphological structure of treated fly ash showed in Figure 4 (fly- $\mathrm{NaOH})$ is rough in comparison with initial ones. There are many cracks and small particles which are aluminum silicate or aluminum sulfate formed from abrasion process on the surface. It was caused by reactions between $\mathrm{NaOH}$ and oxides of fly ash. Although the size of fly ash particles of experiments is not similar, there is no 

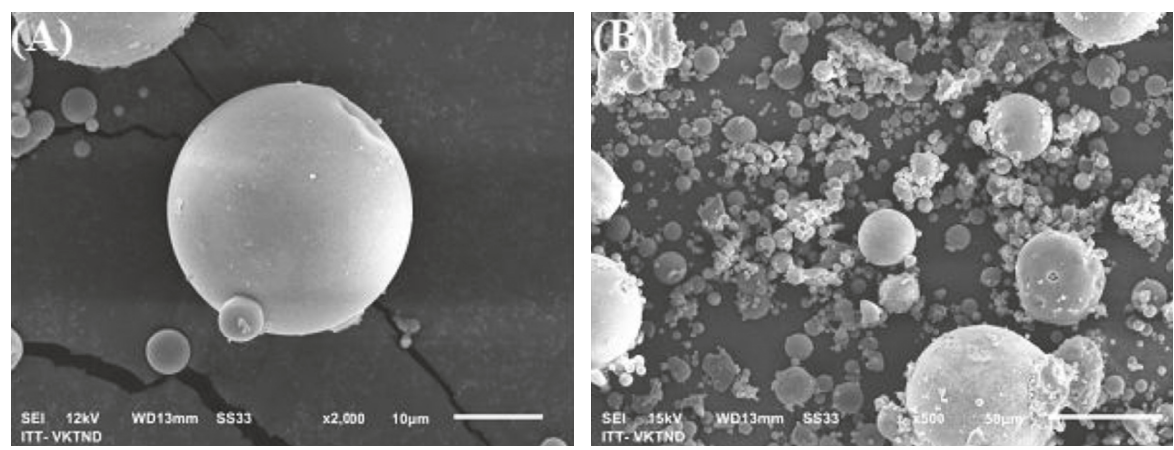

Figure 1: SEM image of fly ash/Epikote 240 composites.

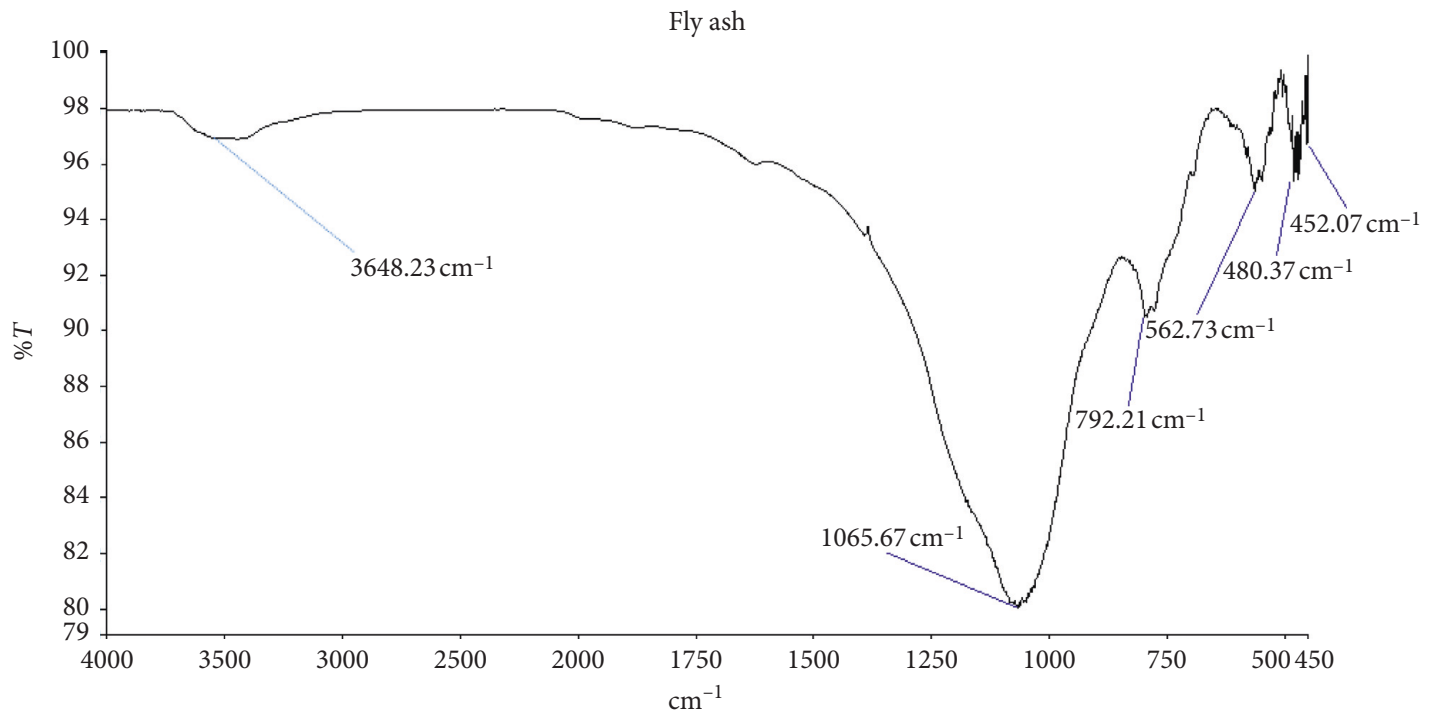

FIGURE 2: IR spectroscopy of the original fly ash sample.

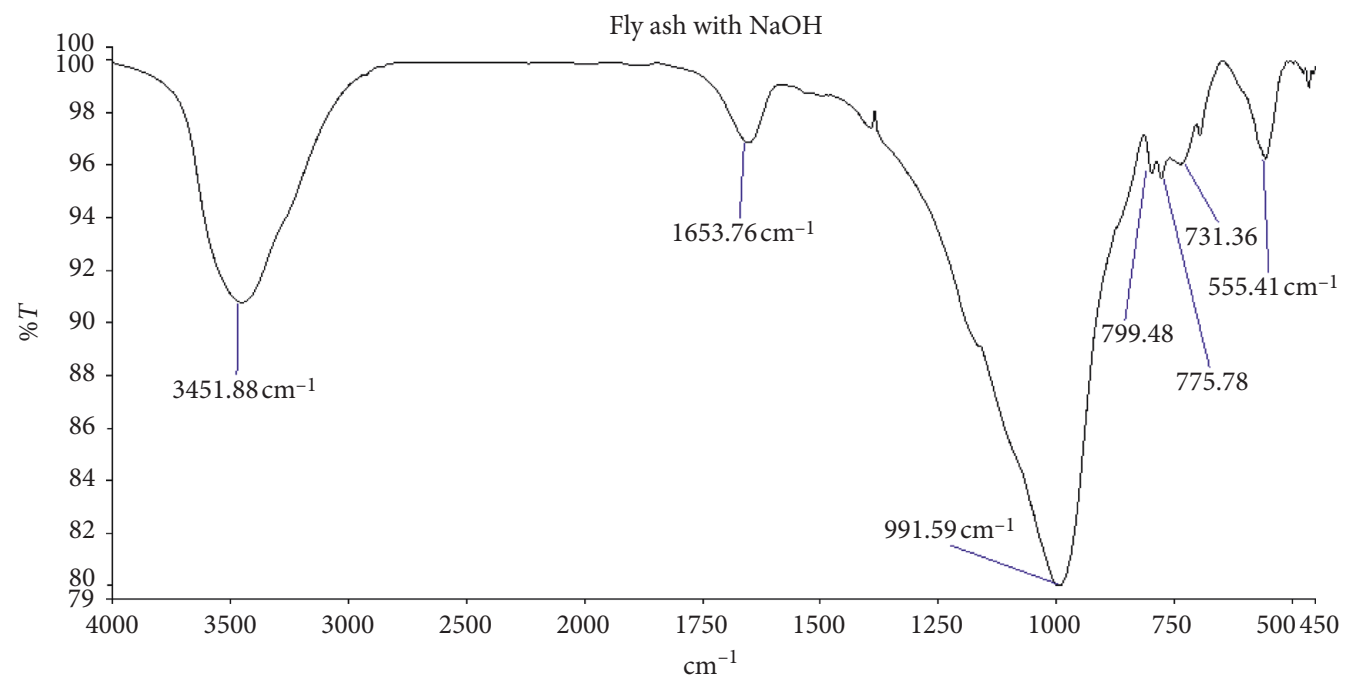

FIGURE 3: IR spectroscopy of the original fly ash- $\mathrm{NaOH}$ sample.

difficulty in enhancing properties of fly ash by this method. The surface becomes rough, and the increase of surface area may make the interaction between fly ash and epoxy resin better.
3.2.2. Treatment of Fly Ash Surface with $\mathrm{HCl}$ Acid

(1) IR Spectroscopy of Fly Ash Modified by $\mathrm{HCl}$ Acid. $\mathrm{HCl}$ is a strong acid used to corrode metallic oxides included in fly 


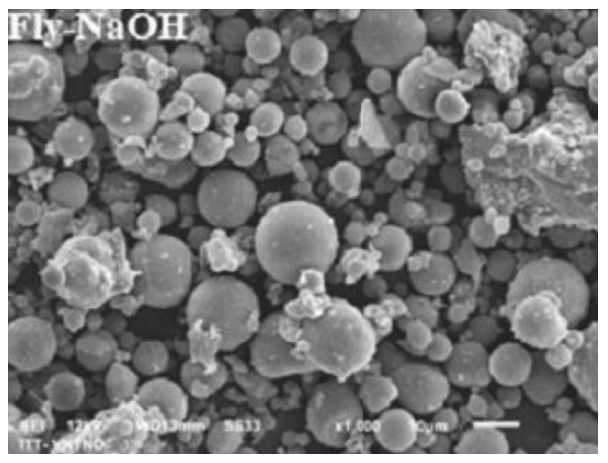

(a)

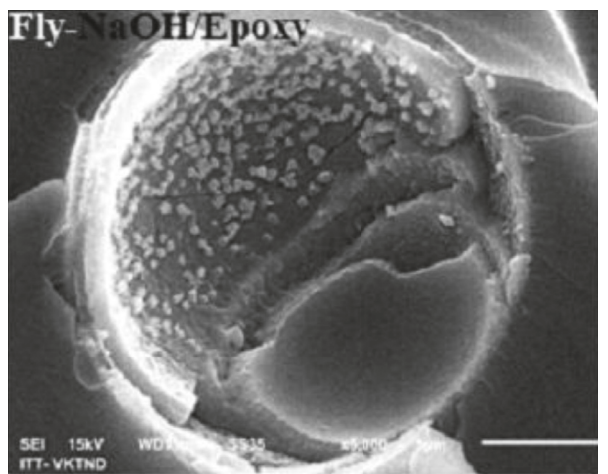

(c)

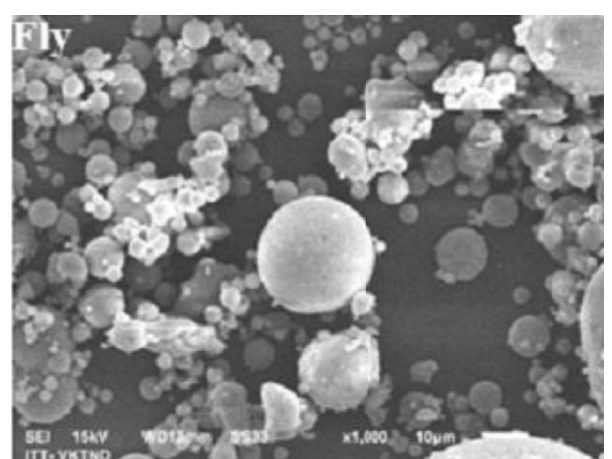

(b)

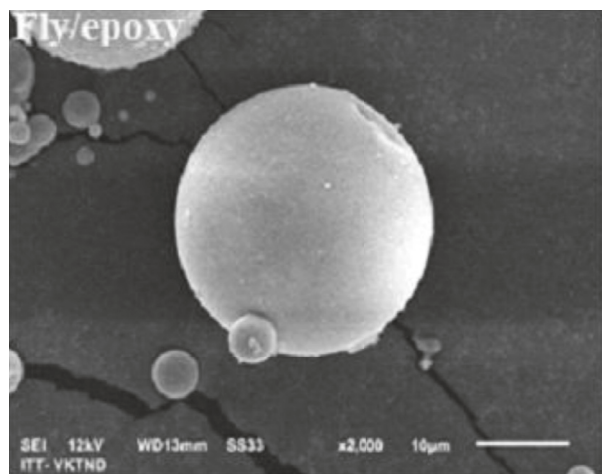

(d)

Figure 4: SEM image of fly ash modified with $\mathrm{NaOH}$. (a) Fly-NaOH: modified fly ash; (b) fly: not yet counted; (c) fly-NaOH/epoxy: composite epoxy resin surface has modified fly ash; and (d) fly/epoxy: composite epoxy resin substrate has unmodified fly ash surface.

ash. The modification process used $2 \mathrm{M} \mathrm{HCl}$ solution. Fly ash particles were stirred in $\mathrm{HCl} 2 \mathrm{M}$, at $95^{\circ} \mathrm{C}$, for 6 hours to modify. By observing peaks appearing on IR spectroscopy of modified fly ash in Figure 5, efficiency of this method was qualitatively evaluated. There is little difference in IR spectroscopy of modified fly ash in comparison with the initial one. This proves a bad compatibility between acid $\mathrm{HCl}$ and fly ash. So, using acid $\mathrm{HCl}$ to change the structure of fly ash is ineffective.

(2) Effects of Acidic Treatment on Fly Ash's Size and Surface Area. The SEM image in Figure 6 is observed to more clearly understand the change of fly ash particles after modified with $\mathrm{HCl}$. Images in other resolutions of modified fly ash particles show that there are crystals attached to fly ash particles, making fly ash surface area rough, thus increasing contact area between fly ash particles and polymer substrate (see Figure 6).

Besides, the size of modified fly ash particles is more even than that of initial ones, making the dispersion of fly ash particles in resin better (see Figure 6). However, there are only crystals but no cracks on fly ash surface. Therefore, it can be concluded that acid $\mathrm{HCl}$ has no strong impact on fly ash and this method is not an optimal one.

\subsection{Study on Preparation of Fly Ash/Epoxy Composites}

3.3.1. Effects of the Amount of Fly Ash Modified by Inorganic Compounds on Mechanical Properties, Flame Retardant Ability, and Structure of the Materials
(1) Effects on Mechanical Properties. Effects of the amount of fly ash modified by inorganic compounds $(\mathrm{NaOH}$ and $\mathrm{HCl})$ on tensile strength of the materials are shown in Figure 7. As a result, materials' tensile strength follows the order: materials including fly ash modified by $\mathrm{NaOH}>$ materials including fly ash modified by $\mathrm{HCl}>$ materials including fly ash without modification. Besides, increasing the amount of fly ash makes tensile strength decrease, but it is insignificant. This shows that the compatibility with resin of modified fly ash is better than of initial fly ash, leading to the increase of tensile strength. Concretely, tensile strength of the materials including 5, 10, and 20 wt.\% of fly ash modified with $\mathrm{NaOH}$ is $82.43,79.20$, and $75.75 \mathrm{MPa}$, respectively. Tensile strength of the materials including 5, 10, and 20 wt.\% of fly ash modified with $\mathrm{HCl}$ is 79.98, 78.39, and $75.37 \mathrm{MPa}$, respectively.

Effects of the amount of fly ash modified by inorganic compounds $(\mathrm{NaOH}$ and $\mathrm{HCl})$ on tensile modulus of the materials are shown in Figure 8. As a result, materials' tensile modulus follows the order: materials including fly ash modified with $\mathrm{NaOH}>$ materials including fly ash without modification $>$ materials including fly ash modified with $\mathrm{HCl}$. Besides, increasing the amount of fly ash makes tensile modulus decrease, but it is insignificant. This shows that the compatibility with resin of modified fly ash is better than of initial fly ash, leading to the stability of tensile modulus. Concretely, tensile modulus of the materials including 5, 10, and 20 wt.\% of fly ash modified with $\mathrm{NaOH}$ is $52.27,49.98$, and $47.75 \mathrm{MPa}$, respectively. Tensile modulus of the 


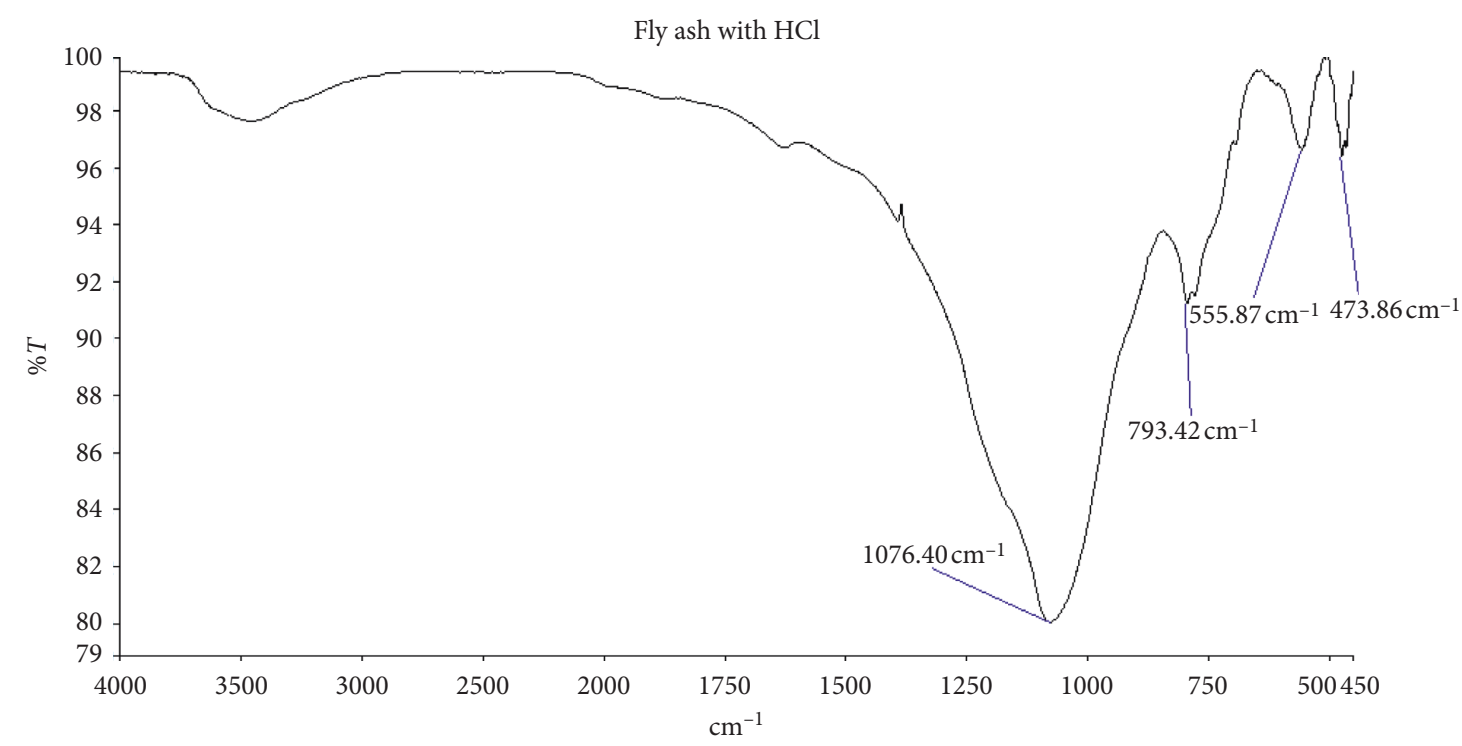

FIGURE 5: IR spectroscopy of the original fly- $\mathrm{HCl}$ ash sample.
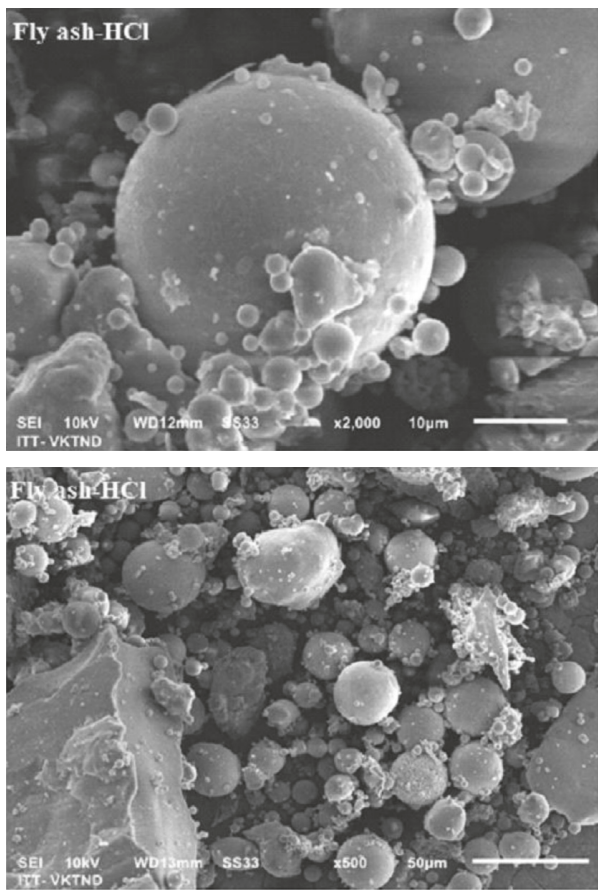

FIgure 6: SEM image of fly ash modified with $\mathrm{HCl}$.

materials including 5, 10, and 20 wt.\% of fly ash modified with $\mathrm{HCl}$ is $45.09,43.79$, and $41.08 \mathrm{MPa}$, respectively.

Figure 9 shows effects of the amount of fly ash modified with inorganic compounds $(\mathrm{NaOH}$ and $\mathrm{HCl})$ on compressive strength of the materials. As a result, materials' compressive strength follows the order: materials including fly ash modified by $\mathrm{NaOH}>$ materials including fly ash modified by $\mathrm{HCl}>$ materials including fly ash without modification. Moreover, impressive strength of the materials significantly increases with the increase of the amount of fly ash. This is caused by the increase in compatibility, adhesion, and filling ability of modified fly ash with resin, thus leading to the improvement of compressive strength. Concretely,

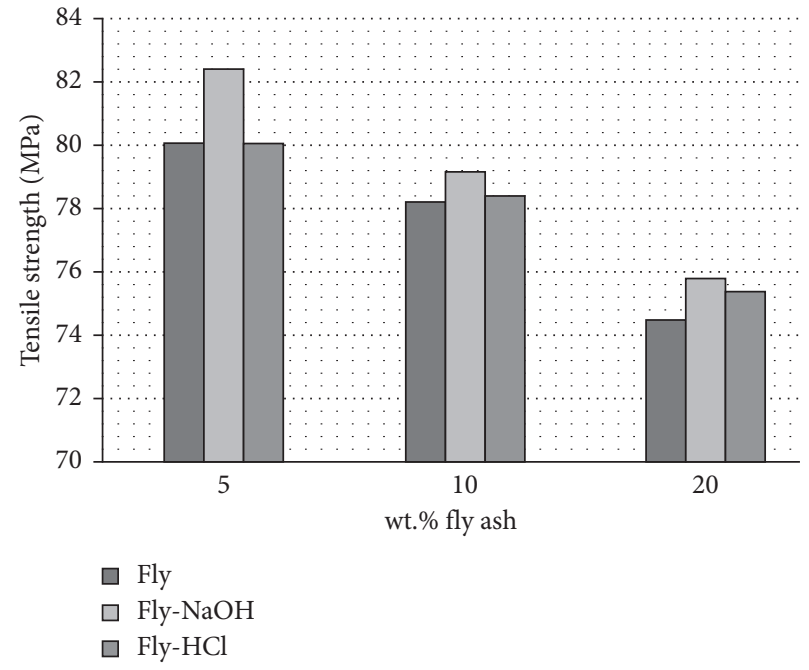

Figure 7: Comparison of flexural strength.

compressive strength of the materials including 5, 10, and 20 wt.\% of fly ash modified with $\mathrm{NaOH}$ is $176.01,189.90$, and 197.07 MPa, respectively. Compressive strength of the materials including 5, 10, and $20 \mathrm{wt} . \%$ of fly ash modified with $\mathrm{HCl}$ is $145.33,180.07$, and $196.78 \mathrm{MPa}$, respectively.

When epoxy resin is cured with diethylenetriamine (DETA), cross-linking forms a three-dimensional space circuit. Fly ash acts as an inorganic filler that loses the space between polymer chains, reducing the flexibility of the polymer molecule to increase hardness. Besides, fly ash particles were filled into spaces between polymers in the epoxy matrix, creating pressure on polymers in the vicinity. As a result, the tension was reduced and the hardness was enhanced. In addition, the adhesion of the particle/matrix has a significant influence on the durability of granular polymer composites. A strong interfering link between particles and polymer matrix is important for effective stress transfer resulting in high intensity of synthesis [5]. 


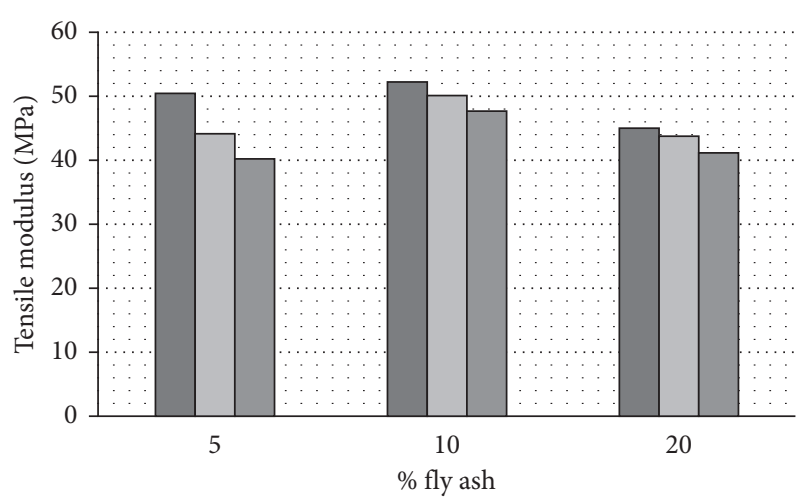

$$
\begin{aligned}
& \square \text { Fly } \\
& \square \text { Fly-NaOH } \\
& \square \text { Fly-HCl }
\end{aligned}
$$

Figure 8: Comparison of tensile strength.

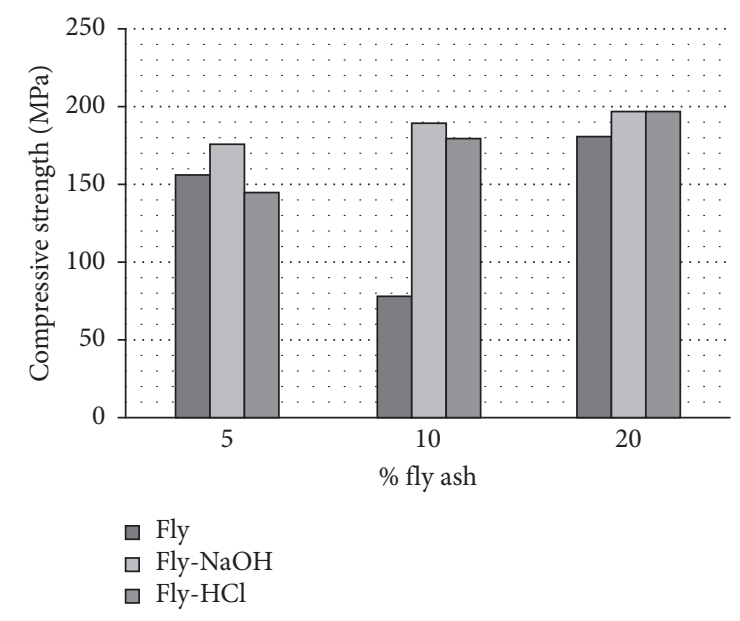

FIGURE 9: Comparison of compressive strength.

Figure 10 shows effects of the amount of fly ash modified with inorganic compounds $(\mathrm{NaOH}$ and $\mathrm{HCl})$ on compact strength of the materials. As a result, materials' compact strength follows the order: materials including fly ash modified by $\mathrm{HCl}>$ materials including fly ash modified by $\mathrm{NaOH}>$ materials including fly ash without modification. Moreover, compact strength of the materials insignificantly decreases with the increase of the amount of fly ash. After modification, compatibility of fly ash with resin is better, leading to the improvement of compact strength. Concretely, compact strength of the materials including 5, 10, and $20 \mathrm{wt} . \%$ of fly ash modified with $\mathrm{NaOH}$ is $6.89,6.01$, and $5.70 \mathrm{MPa}$, respectively. Compact strength of the materials including 5,10 , and $20 \mathrm{wt} . \%$ of fly ash modified with $\mathrm{HCl}$ is $6.54,6.55$, and $5.98\left(\mathrm{~kJ} / \mathrm{m}^{2}\right)$, respectively.

The results show that the amount of fly ash affects mechanical properties of the materials. Like fly ash without modification, there are effects on the materials in the case of modified fly ash such as increasing compressive strength and decreasing tensile modulus, compact strength, and tensile strength. However, effects made by modified fly ash are more significant than by initial fly ash because of good contribution and adhesion of modified fly ash particles with resin.

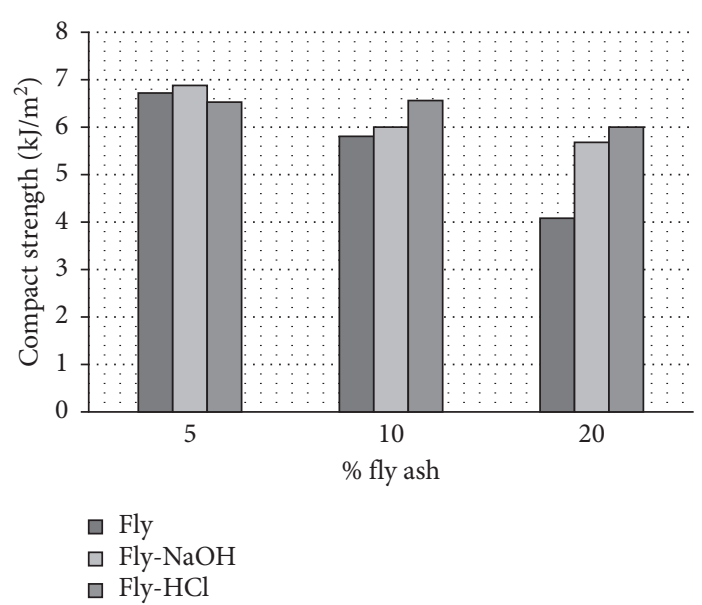

Figure 10: Comparison of compact strength.

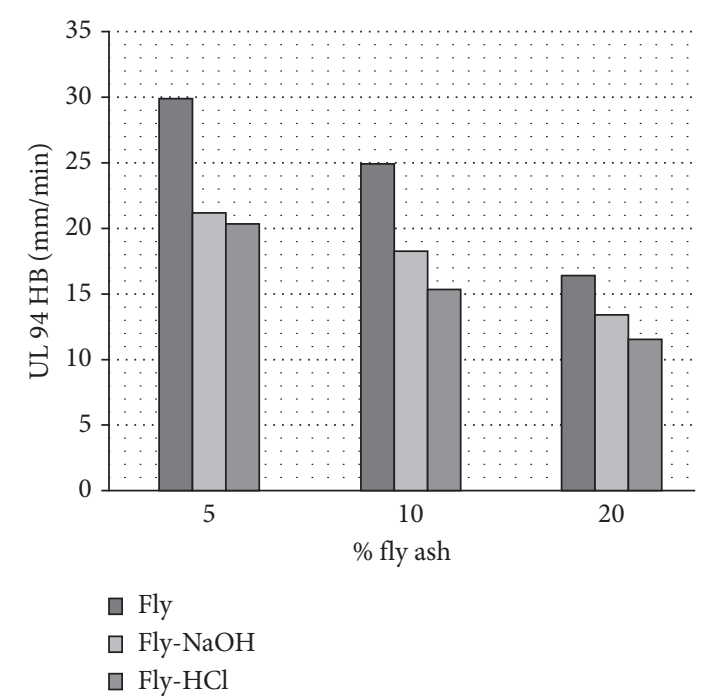

FIGURE 11: Flame retardancy according to the UL 94HB research method.

Thus, fly ash modified with $\mathrm{NaOH}$ is better than fly ash modified with $\mathrm{HCl}$.

(2) Investigation of Effects of the Amount of Fly Ash on Flame Retardancy of the Materials by UL 94 HB Standard. Figure 11 shows effects of the amount of fly ash modified with inorganic compounds $(\mathrm{NaOH}$ and $\mathrm{HCl})$ on the burning rate of the materials following UL $94 \mathrm{HB}$ standard. As a result, the burning rate of the materials follows the order: the materials including fly ash modified with $\mathrm{HCl}<$ the materials including fly ash modified with $\mathrm{NaOH}<$ the materials including fly ash without modifications. Besides, the higher the amount of fly ash is, the lower the burning rate is or the better the flame retardancy of the materials is. This proves that after modification, fly ash's compatibility with resin is better, making flame retardancy of the materials better. Concretely, the burning rate following UL $94 \mathrm{HB}$ standard of the materials including 5, 10, and $20 \mathrm{wt} . \%$ of $\mathrm{NaOH}$ is $21.15,18.22$, and $13.45 \mathrm{~mm} / \mathrm{min}$, respectively. The burning rate following UL $94 \mathrm{HB}$ standard of the materials 


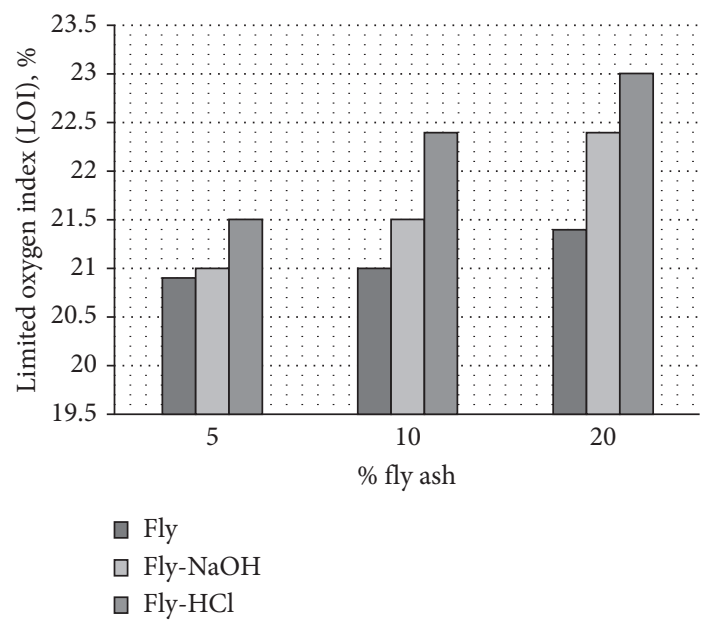

FIGURE 12: Effects of the amount of fly ash on limited oxygen index (LOI).
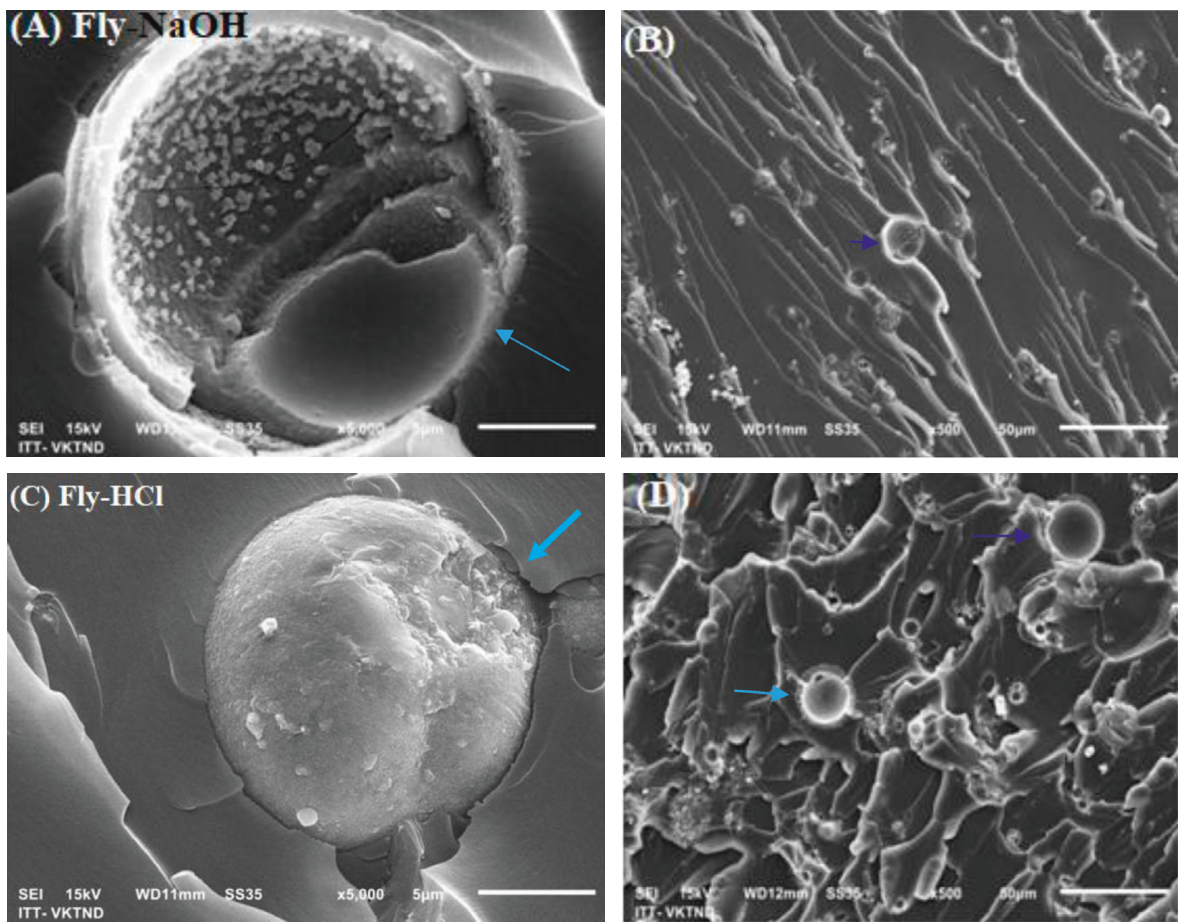

FIGURE 13: SEM image of fly ash modified with $\mathrm{HCl}(\mathrm{C}, \mathrm{D})$ and fly ash modified with $\mathrm{NaOH}(\mathrm{A}, \mathrm{B})$.

including 5,10 , and 20 wt. $\%$ of $\mathrm{HCl}$ is $20.27,15.37$, and $11.51 \mathrm{~mm} / \mathrm{min}$, respectively.

Figure 12 shows effects of the amount of fly ash modified with inorganic compounds $(\mathrm{NaOH}$ and $\mathrm{HCl})$ on LOI of the materials. As a result, LOI of the materials follows the order: the materials including fly ash modified with $\mathrm{HCl}>$ the materials including fly ash modified with $\mathrm{NaOH}>$ the materials including fly ash without modifications. Besides, the higher the amount of fly ash is, the higher the LOI is or the better the flame retardancy of the materials is. This proves that after modification, fly ash's compatibility with resin is better, making flame retardancy of the materials better. Concretely, LOI of the materials including 5, 10, and $20 \mathrm{wt} . \%$ of $\mathrm{NaOH}$ is $21,21.5$, and $22.4 \%$, respectively. LOI of the materials including 5,10 , and $20 \mathrm{wt} . \%$ of $\mathrm{HCl}$ is $21.5,22.4$, and $23 \%$, respectively.

Figures 11 and 12 show that modified fly ash makes flame retardancy of the materials better than initial fly ash. This is caused by the good contact and dispersion of modified fly ash. Among them, fly ash modified with $\mathrm{HCl}$ is better than with $\mathrm{NaOH}$. However, the difference is insignificant. From the aforementioned results, it can be said that the sample including $20 \mathrm{wt} . \%$ of fly ash is the best with stable mechanical properties and good flame retardancy. Therefore, it will be selected for further experiments. 
3.3.2. Effects of the Amount of Fly Ash Modified with Inorganic Compounds on Structure of the Materials. SEM images in Figure 13 show the dispersion and adhesion of modified fly ash in resin. Figure 13 shows fracture surface of the material including 20 wt.\% of fly ash modified with $\mathrm{NaOH}$ and $\mathrm{HCl}$.

For fly ash modified with $\mathrm{NaOH}$, it can be seen that fly ash particles have a broken shell to release smaller inside particles which adhere and contact with resin (Figure 13(a)). Therefore, adhesion ability and contact surface area of fly ash modified with $\mathrm{NaOH}$ are better than of initial one. Besides, there are high density and good contribution of spherical fly ash particles in resin (Figure 13(b)). For fly ash modified with $\mathrm{HCl}$, it can be seen that there are rough surfaces of fly ash particles (Figure 13(c)) leading to the higher contact surface area of modified fly ash than initial ones. Besides, there are also high density and good contribution of spherical fly ash particles in resin (Figure 13(d)).

\section{Conclusions}

In this study, fly ash collected from Vietnamese thermal power plants was modified by $\mathrm{NaOH}$ and $\mathrm{HCl}$ to improve its efficiency and reduce its negative impacts on the environment. The aim is to improve the flame retardant properties and improve some mechanical properties. According to research results, the following conclusions are given:

(i) High compatibility between fly ash (denatured by $\mathrm{NaOH}$ and $\mathrm{HCl}$ ) and epoxy resin substrate. As a result, the fire resistance of the material has been enhanced.

(ii) The interface between fly ash and epoxy resin substrate plays a very important role in improving mechanical properties and flame retardancy of materials. SEM images show that fly ash particles are evenly dispersed into epoxy resin substrate.

(iii) There is an increase in the compressive strength of the material when increasing the fly ash content. Besides, there is decrease in flexural strength, tensile strength, and compact strength but without significant effects on the material.

\section{Data Availability}

For any questions relating to the data or the original data requirements of the article, contact the corresponding author at anhnt@haui.edu.vn.

\section{Conflicts of Interest}

The authors declare that there are no conflicts of interest regarding the publication of this paper.

\section{Acknowledgments}

The authors wish to thank the Faculty of Chemical Technology, Hanoi University of Industry, for funding this work.

\section{References}

[1] H. A. Rahman, S. H. Amirnordin, and N. Khan, "Eco-friendly flame-retardant additives for polyurethane foams: a short review," Key Engineering Materials, vol. 791, pp. 19-28, 2018.

[2] M. Soyama, K. Inoue, and M. Iji, "Flame retardancy of polycarbonate enhanced by adding fly ash," Polymer for Advanced Technologies, vol. 18, no. 5, pp. 386-391, 2007.

[3] M. Singla and V. Chawla, "Mechanical properties of epoxy resin-fly ash composite," Journal of Minerals and Materials Characterization and Engineering, vol. 9, no. 3, pp. 199-210, 2010.

[4] B. T. Phuc, T. V. Dieu, and N. T. Anh, "Improved flame retardant properties of polymers epoxy based on antimonytrioxide/chlorinated paraffin," Materials Science and Engineering: A-Journal, vol. 4, p. 146, 2014.

[5] K. Aschberger, I. Campia, L. Q. Pesudo, A. Radovnikovic, and V. Reina, "Chemical alternatives assessment of different flame retardants-a case study including multi-walled carbon nanotubes as synergist," Environment International, vol. 101, pp. 27-45, 2017.

[6] T. Uygunoglu, I. Gunes, and W. Brostow, "Physical and mechanical properties of polymer composites with high content of wastes including boron," Materials Research, vol. 18, no. 6, pp. 1188-1196, 2015.

[7] N. T. Anh, N. Q. Tung, B. T. Phuc, and N. X. Canh, "The use of multi-walled carbon nanotubes and nanoclay for simultaneously improving the flame retardancy and mechanical properties of epoxy nanocomposites," International Journal of Engineering and Technology, vol. 7, no. 4.36, pp. 1149-1160, 2018. 

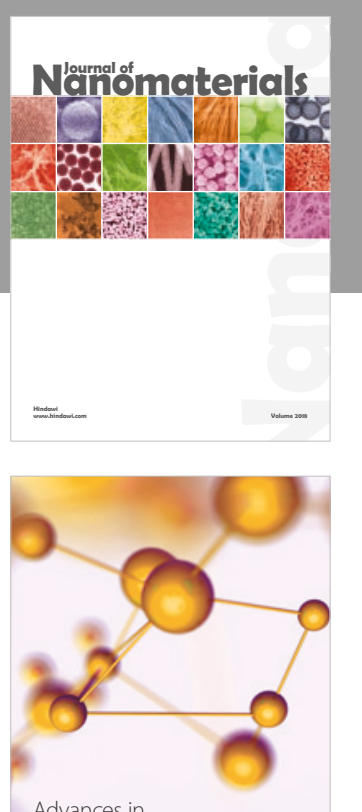

Physical Chemistry
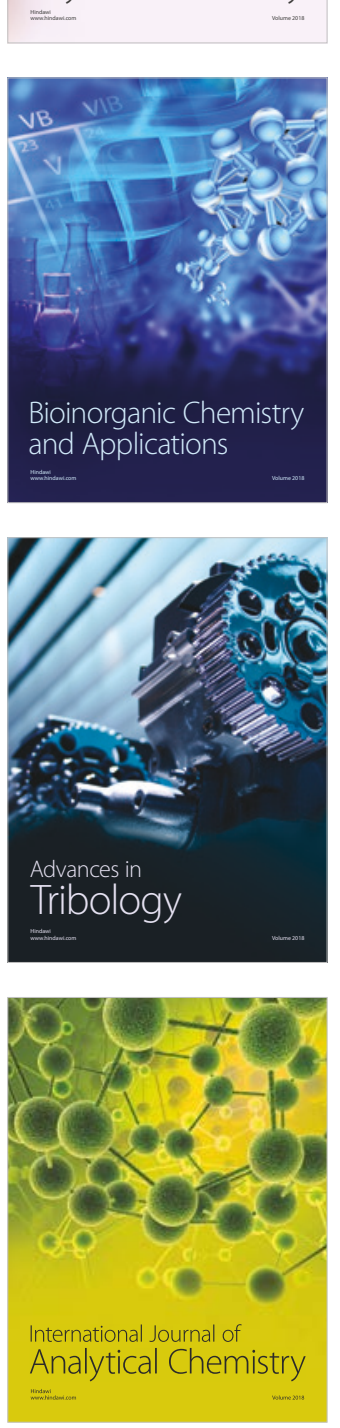

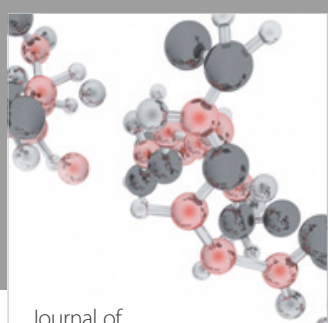

Analytical Methods

in Chemistry

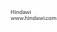

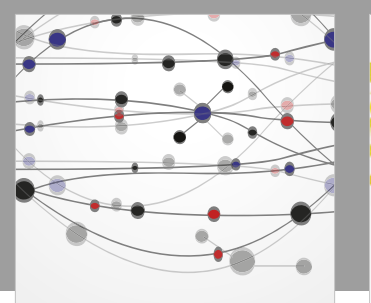

The Scientific World Journal

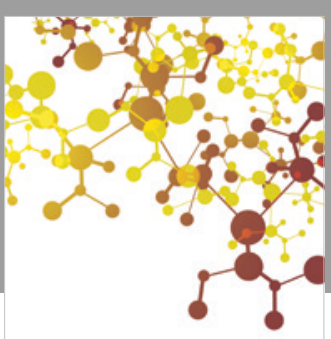

Journal of

Applied Chemistry
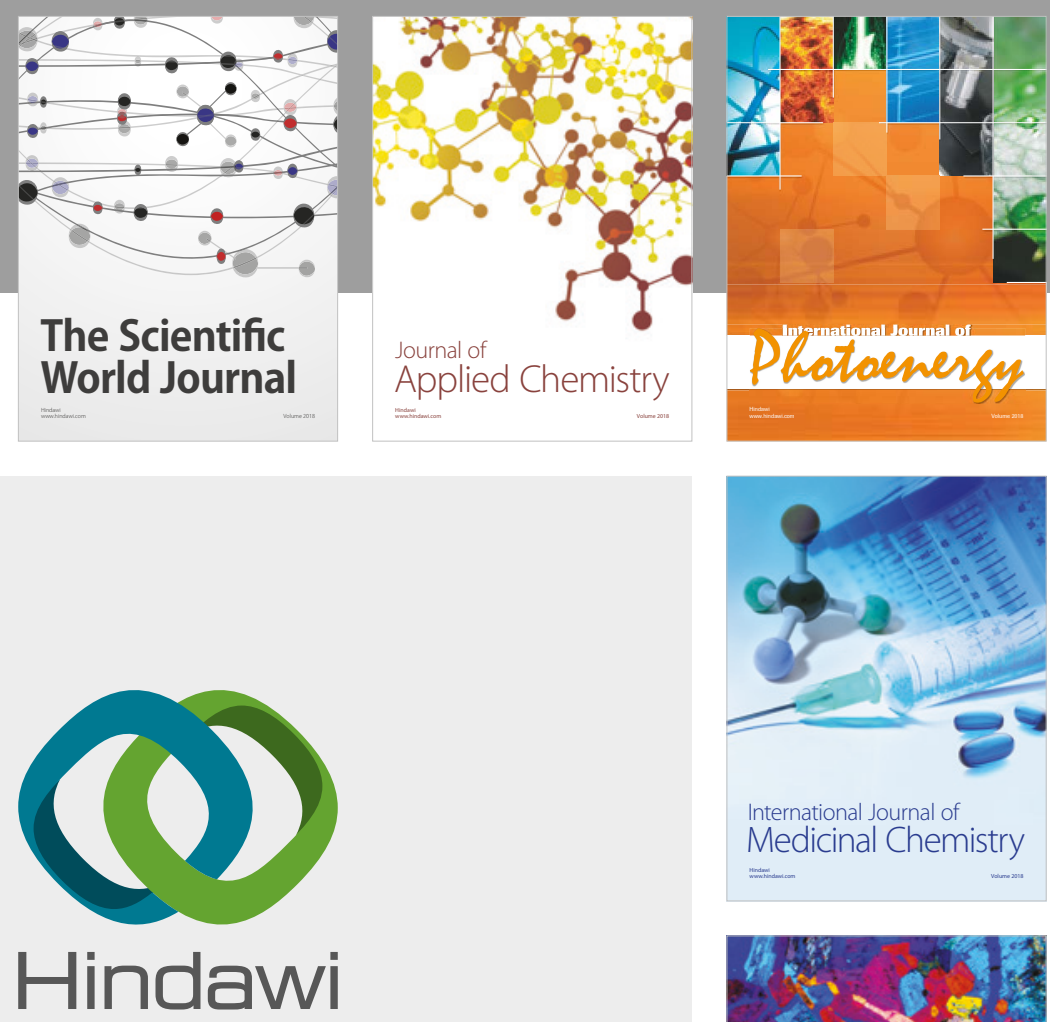

Submit your manuscripts at

www.hindawi.com
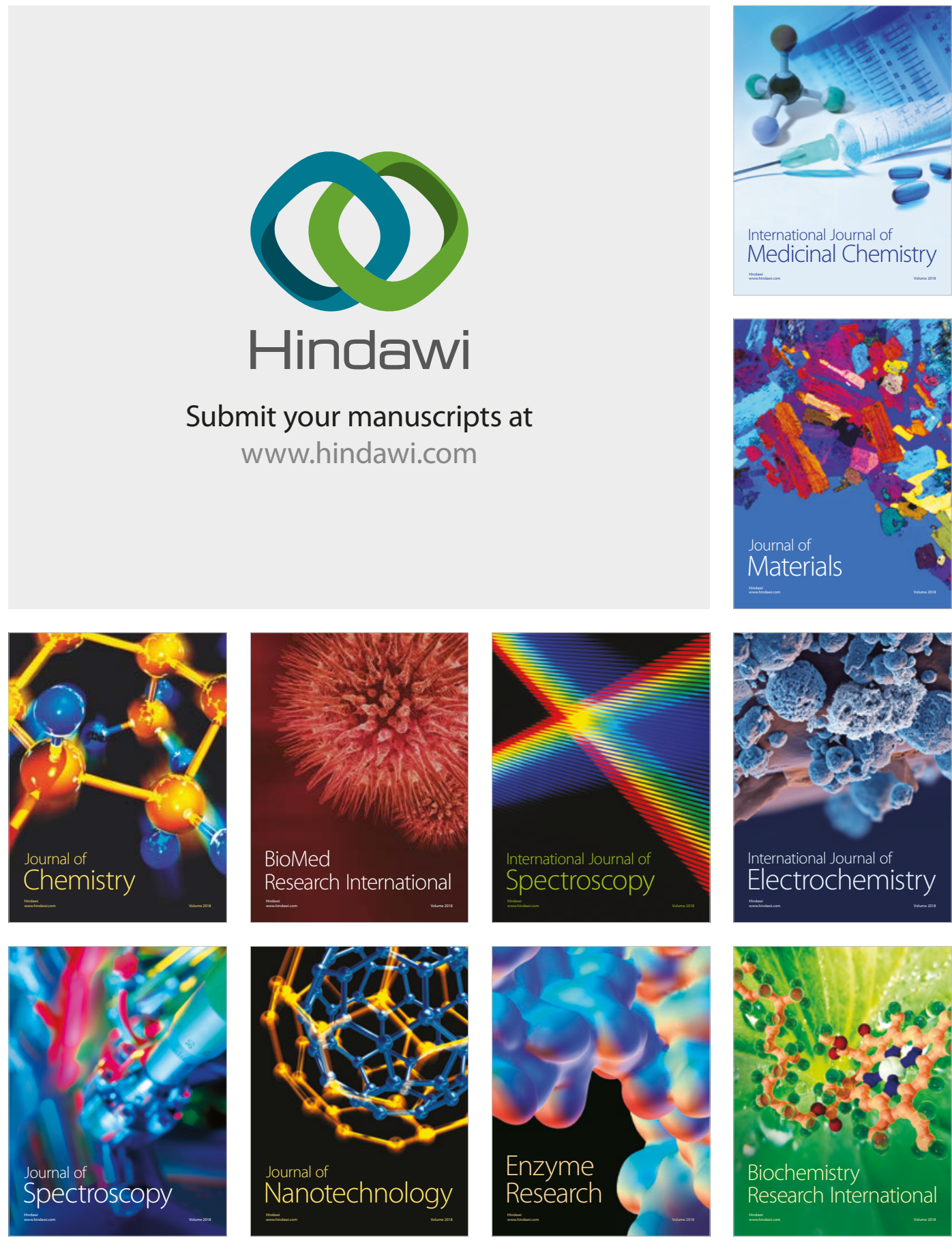
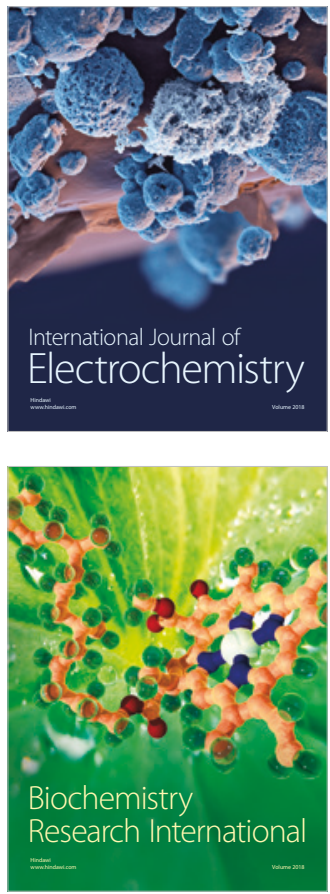